\title{
Absence of HCV RNA from the Peripheral Blood Mononuclear Cells is a Predictor of Good Response after Treatment of Egyptian Chronic Hepatitis C Patients with Sofosbuvir Based Therapy: a prospective study
}

\section{Hanan Mostafa Mostafa}

Alexandria University Medical Research Institute

Mariam Salah Zaghloul ( $\square$ mariam_zaghloul@med.kfs.edu.eg)

Kafrelsheikh University Faculty of Medicine https://orcid.org/0000-0002-4244-5396

Abeer Ghazal

Alexandria University, Medical Research Institute

Dalia Elsayed Ragab

University College London Medical School

Research article

Keywords: HCV treatment; DAAs; chronic hepatitis C; PBMCs; SVR

Posted Date: October 22nd, 2019

DOI: https://doi.org/10.21203/rs.2.13647/v2

License: (9) This work is licensed under a Creative Commons Attribution 4.0 International License.

Read Full License 


\section{Abstract}

Background: Studies indicate that in most patients with chronic hepatitis C, viral RNA is present not only in plasma but also in Peripheral Blood Mononuclear Cells (PBMC). Furthermore, the PBMC compartment may be a preferred site for $\mathrm{HCV}$, which is able to reinitiate viral replication after HCV treatment, even if clearance occurred. The aim of this study was to detect the persistence of hepatitis $\mathrm{C}$ viral RNA in both serum and PBMCs at 12 and 24 weeks of treatment in chronic hepatitis $\mathrm{C}$ virus $(\mathrm{CHC})$ patients with sofosbuvir based therapy. Methods: $75 \mathrm{CHC}$ patients were tested for HCV- RNA in serum at 0, 12 \& 24 weeks of treatment, and for HCV- RNA in PBMCs on the 12 \& 24 weeks. Results: At week 12 of treatment all patients had no HCVRNA in their serum; however, 8 cases were positive for HCV RNA in their PBMC. After 24 weeks of treatment, HCV RNA was re-examined in both serum and PBMCs for all patients. Six out of the eight cases that were found having positive HCV RNA in their PBMCs turned positive HCV RNA in the serum. While the other two cases still negative for HCV RNA in the serum. Interestingly, another two cases out of the sixty-seven cases that were found having negative HCV RNA in their PBMC turned positive HCV RNA in the serum. Conclusions: Absence of HCV RNA in PBMC is a better predictor of good response after treatment of $\mathrm{CHC}$ patients with DAAs, than its absence in the serum.

\section{Background}

Hepatitis C virus (HCV) is infects over 170 million people world-wide. It causes chronic hepatitis in up to $85 \%$ of those infected. In a significant number of patients, chronic hepatitis $\mathrm{C}(\mathrm{CHC})$ eventually progresses to fibrosis and cirrhosis in $35 \%$ of patients, $3 \%$ of whom would develop hepatocellular carcinoma (HCC) $[1,2]$.

The highest prevalence of hepatitis $C$ in the world was found in Egypt. Overall, estimates of the HCV rate in the general population range between 10 and 20\%. In 2015, the prevalence of HCV in Egypt was found to be $10.0 \%$ in the $15-59$ year age groups $[3,4]$. Acute HCV infection is often asymptomatic and the great majority of patients develop chronic hepatitis [5].

HCV screening depends on serological detection of anti HCV antibodies by Enzyme-linked immunosorbent assay (ELISA) that has to be confirmed by detection of HCV- RNA in the serum by reverse transcription polymerase chain reaction (RT-PCR) [6] but both tests do not allow for cell specific localization of HCV. Furthermore, repeatedly negative RT-PCR for HCV-RNA in serum does not conclude the absence of HCV in the liver [7].

$\mathrm{HCV}$ is mainly a hepatotropic virus with minor extrahepatic compartments replication accounting for about $3.1 \%$ of the virus in circulation [8, 9]. Hellings et al first described HCV infection of lymphoid cells in 1985[10]. The minus strand HCV RNA and the replicative intermediate form of HCV were detected in the peripheral blood mononuclear cells (PBMCs) indicating HCV replication inside $[11,12]$

Direct acting antiviral drugs (DAAs) are new drugs that have shown superior efficacy in achieving a sustained virologic response (SVR), the ultimate HCV treatment. They target specific non-structural 
proteins of the virus and results in disruption of viral replication and infection. There are four classes of DAAs, non-structural proteins NS3/4A protease inhibitors (Simiprevir, paritaprevir), NS5B nucleoside polymerase inhibitors (Sofosbuvir), NS5B non-nucleoside polymerase inhibitors (Dasabuvir), and NS5A inhibitors (Daclatasvir) according to their mechanism of action and therapeutic target [13].

National protocol of HCV treatment used in Egyptian Patients infected with HCV (genotype 4) is a combination of daily sofosbuvir and any other direct acting antiviral drugs for 12 weeks. Compared to previously used treatments, sofosbuvir-based regimens provide a higher cure rate, fewer side effects, and a two- to four-fold reduction in duration of therapy. It allows most people to be treated successfully without the use of peg interferon. [14].

The importance of checking for the presence of HCV RNA in PBMC lies in its implication as HCV reservoir. It has been demonstrated that low-level intrahepatic viral load despite negative serum HCV RNA has been associated with viral relapse, particularly in the setting of immune suppression. Moreover, the detection of HCV RNA in PBMC might have important implications for effective therapy and the plane of treatment. [15].

\section{Methods}

The aim of the present study was to investigate the persistence of HCV RNA in both serum and peripheral blood mononuclear cells at 12 and 24 weeks of treatment of Egyptian CHC patients with DAAs.

Study design: observational prospective study

This study was carried out after the approval of the Ethical Committee of Medical Research Institute. A signed informed consent was obtained from all patients enrolled in the study. This study included seventy-five CHC patients selected from the outpatient clinic of the Medical Research Institute, Alexandria University.

Criteria of patients' selection: According to the national protocol of treatment of $\mathrm{CHC}$ in Egypt, they were positive for HCV antibody and HCV RNA before treatment. They were treated with (Sofosbuvir $400 \mathrm{mg}$ \& Daclatasvir 60mg daily for 12 weeks) and had negative serum HCV RNA at week 12 (end of treatment). All patients were eligible and fulfilling the criteria for treatment with DAAs and followed up for 12 weeks of treatment \& 12 weeks after treatment. Exclusion criteria included patients with Child B class liver cirrhosis, platelets $<150000 / \mathrm{mm}^{3}$, uncontrolled diabetes mellitus (HbA1C $>9 \%$ ), renal impairment (e GFR $<60 \%$ ), HCC, except 6 months after intervention aiming at cure with no evidence of activity by dynamic imaging (CT or MRI), extra hepatic malignancy except after 2 years of disease free interval, pregnancy or inability to use effective contraception and those with hepatitis B virus or human immunodeficiency virus infection.

All patients were subjected to complete history taking, thorough clinical examination, Ultrasound abdomen, laboratory investigation including; Renal function tests, fasting blood sugar, Liver enzymes, 
liver function test and complete blood picture were done for all patients before the start of therapy.

Serum sample samples were collected from patients and Reverse transcriptase polymerase chain reaction (RT-PCR) for HCV-RNA was done at 0,12 , and 24 weeks of the treatment. PBMCs were separated from blood samples by Ficoll and used for the detection of HCVRNA at weeks $12 \& 24$ of therapy.

Blood was collected from the patients after overnight fasting in a $10 \mathrm{~mL}$ tube. $5 \mathrm{ml}$ were used for serum serum separation and aliquoted to be stored at $-20^{\circ} \mathrm{C}$. the other $5 \mathrm{mls}$ were used for the separation of PBMC and collected into heparin containing tubes. Immediately after collection, the cells were separated from whole blood by centrifugation on a Ficoll-Hypaque density gradient. Aliquots of $10^{6}$ PBMC was pellet and stored at $-80^{\circ} \mathrm{C}$. [16]

\section{A) Quantitative detection of HCV RNA by reverse transcriptase PCR (RT-PCR) from serum (At 0, 12, 24 weeks of treatment). [17]}

HCV specific RNA was extracted from serum samples (140 $\mu \mathrm{L})$ using QIAamp viral RNA Kit (Qiagen, Hilden, Germany) according to the manufacturer's protocol. Tenml of extracted HCV-RNA was amplified using HCV Qiagen kit (Artus, QS-RGQ (72) ref. 4518366 HCV PCR kit). Real time PCR was performed with the Mx3000P TM (Stratagene) real time PCR system. The procedure included; first, incubation at $50^{\circ} \mathrm{C}$ for 30 min to transcribe viral RNA to cDNA by RT, AmpliTaq gold activation for $95^{\circ} \mathrm{C}$ for $10 \mathrm{~min}$, then 40 cycles of two PCR-step amplification, denaturation for $95^{\circ} \mathrm{C}$ for $15 \mathrm{sec}$, Lastly, annealion and extension at $50^{\circ} \mathrm{C}$ for $1 \mathrm{~min}$ and $72^{\circ} \mathrm{C}$ for $30 \mathrm{~min}$ respectively. The fluorescence detection was then performed.

\section{B) Qualitative detection of HCV RNA from PBMC $[18,19]$}

HCV RNA extraction was performed from $10^{6}$ PMNC cell preparation using Gene JET RNA purification kit (Thermo Scientific) following the manufacturer's protocol. Tenml of extracted HCV-RNA was amplified using My Taq one step RT PCR Kit which is formulated for highly reproducible first strand cDNA synthesis and subsequent PCR in a single tube. The samples were amplified by Veritim ${ }^{\mathrm{9}} \mathbf{9 6 - W e l l}$ Thermal Cycler.

HCV was amplified using the following primers:

P1 (KY 78) 5'CTCGCAAGCACCCTATCAGGCAGT-and

P2 (KY 80) 5'GCAGAAAGCGTCTAGCCATGGCGT amplifying a 245 base pair fragment. Reaction mixtures were subjected to the following thermal profile: Reverse Transcription step for 20 minutes at $45^{\circ} \mathrm{C}$ and one cycle of Polymerase activation step for 1 minutes at $95^{\circ} \mathrm{C}$. followed by Forty cycles of denaturation at $95^{\circ} \mathrm{C}$ for 10 seconds, annealing at $60^{\circ} \mathrm{C}$ for 10 seconds and extension at $72^{\circ} \mathrm{C}$ for 30 seconds. Amplified Samples were then analyzed using $2 \%$ agarose gel electrophoresis.

\section{Results}


Age and sex distribution: Among the 75 cases included in this study $51(68 \%)$ were females and 24 (32\%) were males. Out of the 75 cases included in this study; 9(12\%) were between 25 to 35 years, $45(60 \%)$ were between 36 and 45 and $21(28 \%)$ were between 46 and 60 years old. (Table 1)

Laboratory investigation results: (Table I)

Liver function tests: 48 cases (64\%) had elevated liver enzymes and 27 cases (36\%) had normal liver enzymes before the start of the treatment.

All patients had serum albumin $>3.5 \mathrm{~g}$, serum bilirubin $<1.2 \mathrm{mg}$, platelet count $>150,000 / \mathrm{mm}^{3}$ and INR $<1.2$ before the start of the treatment

HCV -RNA Viral load before treatment: 6 cases (8\%) had viral load less than $10^{4}, 39$ cases (52\%) had viral load ranging from $10^{4}$ to less than $10^{6}$ and 30 cases (40\%) had viral load more than $10^{6}$ before the start of the treatment.

Liver Ultrasonography results: 39 cases (52\%) had normal liver ultrasound picture, 15 cases $(20 \%)$ had Fatty liver and 21 cases (28\%) had liver cirrhosis.

In the present study, no correlation was found between either age with cirrhosis or viral load. Also, no correlation was found either between viral load and cirrhosis or liver enzymes.

HCV RNA distribution in both serum and PBMCs at both weeks (12 and 24) of treatment: At the beginning of the treatment, the 75 patients had viral loads ranging from $10^{3}$ to $10^{7} \mathrm{IU} / \mathrm{ml}$. All patients enrolled in this study showed end of treatment response to therapy at week $12(100 \%)$. However, after 12 weeks of treatment, only 8 cases $(10.7 \%)$ out of 75 chronic HCV included in this study were HCV RNA positive in their PBMC. After 24 weeks of treatment, HCV RNA was re-examined in both serum and PBMC for all patients. Six out of the eight cases that were found having positive HCV RNA in their PBMCs turned positive HCV RNA in the serum. While the other two cases became negative for HCV RNA in both serum and PBMC. Interestingly, another two new cases out of the sixty-seven cases that were found having negative HCV RNA in their PBMC turned positive HCV RNA in the serum. SVR at week 24 was achieved in sixty-seven cases out of the seventy-five cases included in the study (89.3\%). Table II, Figure (1\&2).

Comparison between SVR rate in patients positive and negative for HCV RNA in PBMC at the end of treatment: SVR rate is significantly higher in Patients negative for HCV RNA at both serum and PBMCs (97\%) than those who were negative for HCV RNA at the serum but positive in PBMCs at the end of treatment $(25 \%) .\left(x^{2}=38.896\right)(P<0.001)$. (Table III)

\section{Discussion}

Our study demonstrates no correlation between the HCV viral load and the age of the patients, which was also supported by previous studies $[20,21]$. Both a direct viral effect and an immune-mediated response 
may play a role in the pathogenesis of liver injury by HCV [22]. However, no such correlation between viral load and degree of liver injury was found in the present study.

Studies evaluating the relationship between serum viral load and the severity of abnormalities in liver reported conflicting results; as some studies correlated high level viremia with advanced stage liver disease [23] while others found no correlation with either cytology or aminotransferase activities [24-26].

No correlation was found between liver enzymes and viral load in the current study. Similar results were demonstrated by other investigators [27-30].

Direct acting antiviral drugs (DAAs) are new drugs that have shown $>90 \%$ efficacy in achieving the goal of treatment of chronic HCV infection which is a sustained virologic response (SVR). [13]. All CHC patients included in this study were treated with DAAs and showed a higher SVR rate to therapy (89.3\%) defined as the complete absence of detectable serum HCV RNA at week 24 of therapy. This high SVR rate was due to a good selection of the cases as all cases were child $(A)$.

Lymphoid cells may offer favorable reservoirs leading to HCV persistence and chronicity. The latency of HCV virus is still poorly understood [31] Some studies stated that in most patients with chronic hepatitis $C$ showed simultaneous coexistence of viral RNA in plasma and in PBMC. The persistence of HCV RNA in extrahepatic reservoirs could markedly affect disease management. So, despite clearance of HCV from hepatocytes is achieved by treatment, re-infection from extra-hepatic sites, such as the PBMC may occur $[32,33]$

All patients included in this study showed viral response to therapy at week 12 , however, at the same time, HCV RNA was still detected in freshly isolated peripheral blood mononuclear cells of $(10.7 \%)$ of them. After 24weeks of initiating treatment, these patients were retested for the presence of HCV RNA in both serum and PMNCs. Six out of the eight cases that were found having positive HCV RNA in their PBMCs turned positive HCV RNA in the serum. While the other two cases still negative for HCV RNA in the serum. And interestingly another two new cases out of the sixty-seven cases that were found to have negative HCV RNA in their PBMCs turned positive HCV RNA in the serum. This denotes that although patients showed complete response at 12 weeks, it did not signify that the patients would acquire sustained viral response.

In addition to the detection of positive-stranded HCV RNA in PBMC, the presence of negative- stranded HCV RNA in PBMC implies viral replication as well as argues against serum viral particles passively adhering to the cells. [34,35] Moreover, cytoplasmic staining of the monocyte fraction of PBMC for HCV core antigen proves the hypothesis that PBMC contain virus [36]. Also, in chronic HCV patients, HCV genome was detected in PBMC by in situ hybridization. Lastly, HCV-RNA sequences were found in the PBMC, but negative in serum containing the cell preparation of some patients [37].

Similar results were reported by Philippe, who found that $77 \%$ of chronic HCV patients were HCV RNA positive in PBMCs [38] In addition, it was found that the positivity of HCV RNA in PBMC could occur 
concomitantly with negative HCV RNA in serum. Similarly, Ping et al [39] showed that the positive rate of HCV RNA in PBMC of patients with chronic hepatitis $\mathrm{C}$ was much higher than that of patients with acute hepatitis C.

Abdelfattah et al [40] reported the presence of detectable HCV RNA in the PBMCs of $12 \%$ of patients at week 12 of treatment, and all patients were negative for HCV RNA in their sera at the end of the course of interferon based treatment and at the same time, HCV RNA was still detected in freshly isolated peripheral blood mononuclear cells of approximately $32 \%$ of these patients.

Abdelfattah et al [40] observed that patients who tested positively for HCV RNA in PBMCs at the end of treatment had a higher relapse rate $(50 \%)$ when compared with patients who tested negatively for HCV RNA in both serum and PBMCs at the end of treatment (6\%). These results were in accordance with our findings, as we found a significant higher relapse rate in patients who tested positively for HCV RNA in PBMC at the end of treatment (75\%) when compared with patients who tested negatively for HCV RNA in both serum and PBMCs at the end of treatment (3\%). This may give a clue to the role played by the persistence of HCV RNA in PBMC on the outcome of the treatment.

Similar results were reported by Zayed et al. [41] and Gong et al. [42], they suggested that one of the factors influencing response to HCV therapy would be the replicative minus-strand HCV RNA in PBMCs.

On the other hand, Bernardin et al. [43] could not find any detectable HCV RNA in PBMC of 69 non-viremic donors. He implied that PBMCs are unlikely to serve as a long-lived reservoir of HCV in non-viremic subjects. But this cannot role out effective replication of HCV in the PBMCs in those exposed to HCV infection.

\section{Conclusions}

Absence of HCV RNA in PBMCs is a better predictor of good response after treatment of $\mathrm{CHC}$ patients with DAAs, than its absence in the serum.

\section{Abbreviations}

\begin{tabular}{lll} 
CHC & $:$ & chronic hepatitis $\mathrm{C}$ virus \\
DAAs & $:$ & Direct acting antiviral drugs \\
\hline ELISA & $:$ & Enzyme-linked immunosorbent assay \\
HCV & $:$ & hepatitis C virus \\
PBMC & $:$ & Peripheral Blood Mononuclear Cells \\
RT-PCR & $:$ & reverse transcription polymerase chain reaction \\
SVR & $:$ & sustained virologic response
\end{tabular}




\section{Declarations}

\section{Ethics approval and consent to participate}

All procedures performed in studies involving human participants were in accordance with the ethical standards of Alexandria University, Medical Research Institute ethical committee and with the 1964 Helsinki declaration and its later amendments or comparable ethical standards. All participants signed an informed consent.

Consent to publish: Not applicable

\section{Availability of data and materials}

The data that support the findings of this study are available from [Alexandria Medical research Institute] but restrictions apply to the availability of these data, which were used under license for the current study, and so are not publicly available. Data are however available from the authors upon reasonable request and with permission of [Alexandria Medical research Institute].

\section{Competing Interests}

The authors declare no conflicts of interest.

\section{Funding}

Not applicable.

\section{Authors' contributions}

HM contributed to concept and design, data collection, writing of article, analysis and interpretation of data, statistical analysis and critical revision of the manuscript for important intellectual content.

MZ contributed to experiments and procedures; drafting of the manuscript; analysis and interpretation of data; statistical analysis; technical and material support.

AG contributed to experiments and procedures; concept and design, admirative support and critical revision of the manuscript for important intellectual content.

DR contributed to experiments and procedures; concept and design, admirative support and critical revision of the manuscript for important intellectual content.

\section{Acknowledgements}

The authors would like to thank all those who helped in this work especially the nursing staff and laboratory technicians. 


\section{References}

1. WHO: Hepatitis C. World Health Organization Fact Sheet $N^{\circ} 164$. https://www.who.int/newsroom/fact-sheets/detail/hepatitis-c. Accessed 15 July 2019.

2. Freeman AJ, Dore GJ, Law MG, Thorpe M, Von Overbeck J, Lloyd AR, et al. Estimating progression to cirrhosis in chronic hepatitis C virus infection. Hepatology. 2001 ;34(4 Pt 1):809-16.

3. Ministry of Health and Population [Egypt], El-Zanaty and Associates, ICF International. Egypt Health Issues Survey 2015. Cairo, Rockville, MD: Ministry of Health and Population, ICF International; 2015.

4. Lavanchy. Evolving epidemiology of hepatitis C virus, Clin Microbiol Infect. 2011;17(2) 107-115.

5. Kolykhalov AA, Agapov EV, Blight KJ, Mihalik K, Feinstone SM, Rice CM. Transmission of hepatitis C by intrahepatic inoculation with transcribed RNA. Science.1997; 277(5325):570-4.

6. Miller RH, Purcell RH. Hepatitis $\mathrm{C}$ virus shares amino acid sequence similarity with pestiviruses and flaviviruses as well as members of two plant virus supergroups. Proc Natl Acad Sci U S A. 1990; 87(6):2057-61.

7. Blackard JT, Kemmer N, Sherman KE. Extrahepatic replication of HCV: insights into clinical manifestations and biological consequences. Hepatology. 2006; 44(1):15-22.

8. Pawlotsky JM. Diagnostic tests for hepatitis C. J Hepatol. 1999; 1:71-9.

9. Dahari H, Feliu A, Garcia-Retortillo M, Forns X, Neumann AU. Second hepatitis C replication compartment indicated by viral dynamics during liver transplantation. J Hepatol. 2005; 42(4):491-8.

10. Hellings JA VdV-dPJ, SneltingVAnDEnsen R, Stute R. Preliminary results of transmission experiments of non-A, non-B hepatitis by mononuclear leucocytes from chronic patient. J Virol Methods. 1985; 10:321-6.

11. Cheng JL, Liu BL, Zhang Y, Tong WB, Yan Z, Feng BF. Hepatitis $C$ virus in human B lymphocytes transformed by Epstein-Barr virus in vitro by in situ reverse transcriptase-polymerase chain reaction. World J Gastroenterol. 2001; 7(3):370-5.

12. Schmidt WN, Wu P, Brashear D, Klinzman D, Phillips MJ, LaBrecque DR, et al. Effect of interferon therapy on hepatitis $C$ virus RNA in whole blood, plasma, and peripheral blood mononuclear cells. Hepatology. 1998;28(4):1110-6.

13. Scheel TK, Rice CM. Understanding the hepatitis $C$ virus life cycle paves the way for highly effective therapies. Nat Med 2013; 19:837-49.

14. European Association for the Study of the Liver. EASL Recommendations on Treatment of Hepatitis C. Journal of Hepatology.2016.

15. Zignego AL, Giannini C, Monti M, Gragnani L. Hepatitis C virus lymphotropism: lessons from a decade of studies. DigLiver Dis. 2007; 39 Suppl 1: S38-S45, Gragnani L Hepatitis C.

16. Böyum A. Isolation of mononuclear cells and granulocytes from human blood. Isolation of monuclear cells by one centrifugation, and of granulocytes by combining centrifugation and sedimentation at 1 g. Scand J Clin Lab Invest Suppl. 1968; 97:77-89.]. 
17. Brown E A, Zhang H, Ping L H, Lemon S M. Secondary structure of the 5 ' nontranslated regions of hepatitis C virus and pestivirus genomic RNAs. Nucleic Acids Res. 1992; 20:5041-5045.

18. Tsukiyama- Kohara K, Lizuka N, Kohara M, et al. Internal ribosome entry site within hepatitis $\mathrm{C}$ virus RNA. J Virol. 1992; 66(3):1476-83.

19. Hellen C and Pestova T. Translation of hepatitis C virus RNA. J Viral Hepatitis.1999; 6:79-88.

20. Matthews-Greer JM, Caldito GC, Adley SD, et al. Comparison of hepatitis C viral loads in patients with or without human immunodeficiency virus. Clin Diagn Lab Immunol. 2001;8:690-4.

21. Schijman A, Colina R, Mukomolov S, et al. Comparison of Hepatitis C Viral Loads in Patients with or without Coinfection with Different Genotypes. Clin Diagn Lab Immunol. 2004;11(2):433-5.

22. Kumar U, Thomas HC, Monjardino J. Serum HCV RNA levels in chronic HCV hepatitis measured by quantitative PCR assay; correlation with serum AST. J Virol Methods. 1994; 47(1-2):95-102.

23. Gretch $D$, Corey $L$, Wilson $J$, et al. Assessment of hepatitis $C$ virus RNA levels by quantitative competitive RNA polymerase chain reaction: high-titer viremia correlates with advanced stage of disease. J Infect Dis. 1994; 169(6):1219-25.

24. McGuinness PH, Bishop GA, Painter DM, et al. Intrahepatic hepatitis C RNA levels do not correlate with degree of liver injury in patients with chronic hepatitis C. Hepatolog. 1996 ;23(4):676-687.

25. Lau GK, Jane WS, Davis G, et al. Detection of hepatitis C virus (HCV) genome in liver by in-situreverse transcription polymerase chain reaction (IS-RT-PCR). Gastroenterology. 1994; 44:406-9.

26. Marrone A, K.D, Mahaney K, et al. The significance of hepatic HCV RNA: analysis by semiquantitative in-situ hybridization. Hepatology. 1994; 20: A236.

27. Adinolfi L E, Utili R, Andreana A. et al. Relationship between genotypes of hepatitis $C$ virus and histopathological manifestations in chronic hepatitis C patients. Eur J Clin Gastroenterol Hepatol. 2000; 12(3):299-304.

28. Lau JY, Kniffen J, Qian KP, et al. Significance of serum hepatitis C virus RNA levels in chronic hepatitis C. Lancet. 1993; 41:1510-14.

29. Nousbaum JB, Pol S, Nalpas B, Landais P, Berthelot P, Bréchot C. Hepatitis C virus type $1 \mathrm{~b}$ (II) infection in France and Italy. Collaborative Study Group. Ann Intern Med. 1995 Feb 1;122(3):161168

30. McCormick SE, Goodman ZD, Maydonovitch CL, et al. Evaluation of liver histology, ALT elevation, and HCV RNA titer in patients with chronic hepatitis C. Am J Gastroenterol. 1996;1:1516-22.

31. Chang TT, Young KC, Yang YJ, et al.Hepatitis $C$ virus RNA in peripheral blood mononuclear cells: comparing acute and chronic hepatitis C virus infection. Hepatology. 1996; 23:977-81.

32. Radkowski M, Wilkinson J, Nowicki M, et al. Search for Hepatitis C Virus Negative-Strand RNA Sequences and Analysis of Viral Sequences in the Central Nervous System: Evidence of Replication. J Virol. 2002; 76(2):600-8.

33. Blackard JT, Kemmer N, Sherman KE. Extrahepatic replication of HCV: insights into clinical manifestations and biological consequences. Hepatology. 2006 ;44 (1): 15-22. 
34. Muller M, Pfaff E, Goeser T, et al. Peripheral blood leukocytes serve as a possible extrahepatic site for hepatitis C virus replication. J Gen Virol. 1993;74(Pt 4):669-76.

35. Wang JT, Shen JC, Lin JT, et al. Detection of replicative from of hepatitis C virus RNA in peripheral blood mononuclear cells. J Infect Dis. 1992; 166:1167-9.

36. Bouffard P, Hayashi PH, Acevedo R, et al. Hepatitis $\mathrm{C}$ virus is detected in a monocyte/macrophage subpopulation of peripheral blood mononuclear cells of infected patients. J Infect Dis. 1992; 166:1276-80.

37. Muratori L, Giostra F, Cataleta $M$, et al. Testing for hepatitis $C$ virus sequences in peripheral blood mononuclear cells of patients with chronic hepatitis $C$ in the absence of serum hepatitis $C$ virus RNA. Liver. 1994; 14:124-8.

38. Philippe H, M.B., Denis O, et al. Occult Hepatitis C Virus Infection Revisited with Ultrasensitive RealTime PCR Assay. J of Clin Mic. 2008; 46(6):2106-8.

39. Ping Z, You C, Mu S, et al. Hepatitis $C$ virus RNA detection in serum and peripheral blood mononuclear cells of patients with hepatitis C. China Nati. J New Gastroenterol. 1997;3(2):108-10.

40. Abdel Fatah F, Khaled M, Ayman F, et al. HCV RNA in peripheral blood mononuclear cells (PBMCs) as a predictor of the response to antiviral therapy in chronic hepatitis $\mathrm{C}$. Alexandria Journal of Medicine. 2014; 50:317-22.

41. Zayed RA, Rushdy E, Saleh D. Detection of HCV RNA in the peripheral blood mononuclear cells of serum HCV RNA-negative Egyptian patients under interferon treatment. Am J Med Sci. 2010;340(6):435-8.

42. Gong GZ, Lai LY, Jiang YF, et al. HCV replication in PBMC and its influence on interferon therapy. World J Gastroenterol. 2003;9(2):291-4.

43. Bernardin F, Tobler L, Walsh I, et al. Clearance of hepatitis $C$ virus RNA from the peripheral blood mononuclear cells of blood donors who spontaneously or therapeutically control their plasma viremia. Hepatology. 2008; 47(5):1446-52.

\section{Tables}

Table I: laboratory investigations and liver ultrasound results in the 75 studied chronic hepatitis $\mathrm{C}$ patients 


\begin{tabular}{|c|c|c|}
\hline Data & Results & Number (\%) \\
\hline Liver enzymes & Elevated & $48(64 \%)$ \\
(ALT \&AST) & Normal & $27(36 \%)$ \\
\hline Viral load of HCV RNA & viral load $<10^{4}$ & $6(8 \%)$ \\
& $10^{4} \leq$ viral load<106 & $39(42 \%)$ \\
& Viral load $\geq 10^{6}$ & $30(50 \%)$ \\
\hline \multirow{2}{*}{ Liver ultrasound } & Normal & $39(42 \%)$ \\
& Fatty liver & $15(20 \%)$ \\
& Liver cirrhosis & $21(28 \%)$ \\
\hline
\end{tabular}

Table II: HCV RNA distribution in both serum and PBMCs at both weeks (12 and 24) of treatment.

\begin{tabular}{|c|c|c|c|c|c|c|c|}
\hline \multicolumn{4}{|c|}{ HCV-RNA in the serum } & \multicolumn{4}{c|}{ HCV-RNA in PBMC } \\
\hline 12 weeks of treatment & 24 weeks of treatment & 12 weeks of treatment & 24 weeks of treatment \\
\hline Positive & negative & positive & negative & positive & negative & Positive & negative \\
\hline $0(0 \%)$ & $75(100 \%)$ & $8(10.7 \%)$ & $67(89.3 \%)$ & $8(10.7 \%)$ & $67(89.3 \%)$ & $6(8 \%)$ & $69(92 \%)$ \\
\hline
\end{tabular}

Table III: Comparison between SVR rates in patients positive and negative for HCV RNA in PBMNC at the end of treatment.

\begin{tabular}{|l|c|}
\hline & $*$ SVR at week24 \\
\hline $\begin{array}{l}\text { Patients negative for HCV RNA at both serum and PBMCs at the end of } \\
\text { treatment }(\mathrm{n}=67)\end{array}$ & $65 / 67(97 \%)$ \\
$\begin{array}{l}\text { Patients negative for HCV RNA at the serum but positive in PBMCs at } \\
\text { the end of treatment }(\mathrm{n}=8)\end{array}$ & $2 / 8(25 \%)$ \\
\hline
\end{tabular}

${ }^{*} \mathrm{X}^{2}=38.896 \quad \mathrm{P}<0.001$

\section{Figures}



1
23
45
6
7

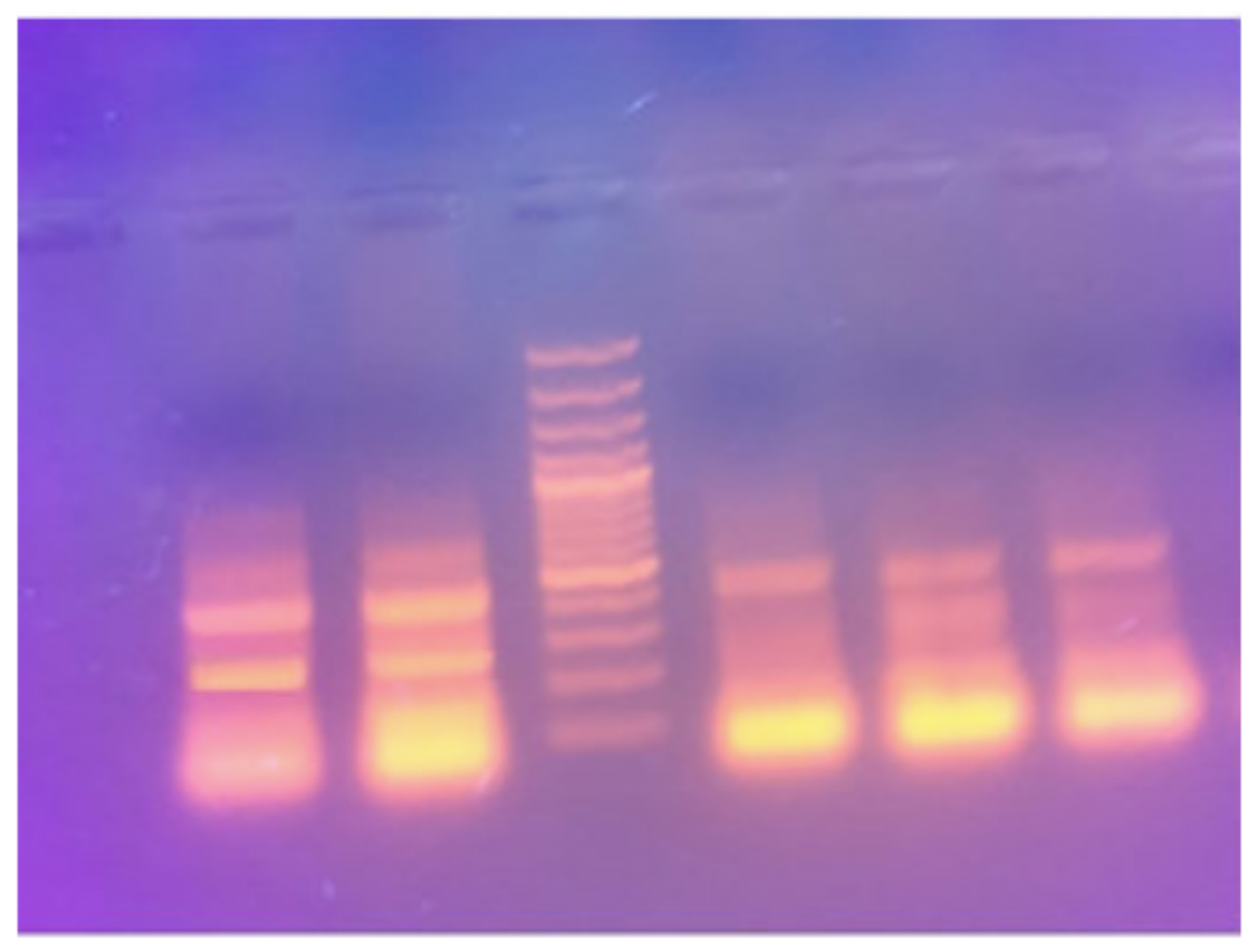

\section{Figure 1}

Ethidium bromide stained $2 \%$ agrose gel showing amplified product of HCV RNA in PMNs (245bp) at lane 2and lane 3 , lane 4 shows a 100bp ladder.

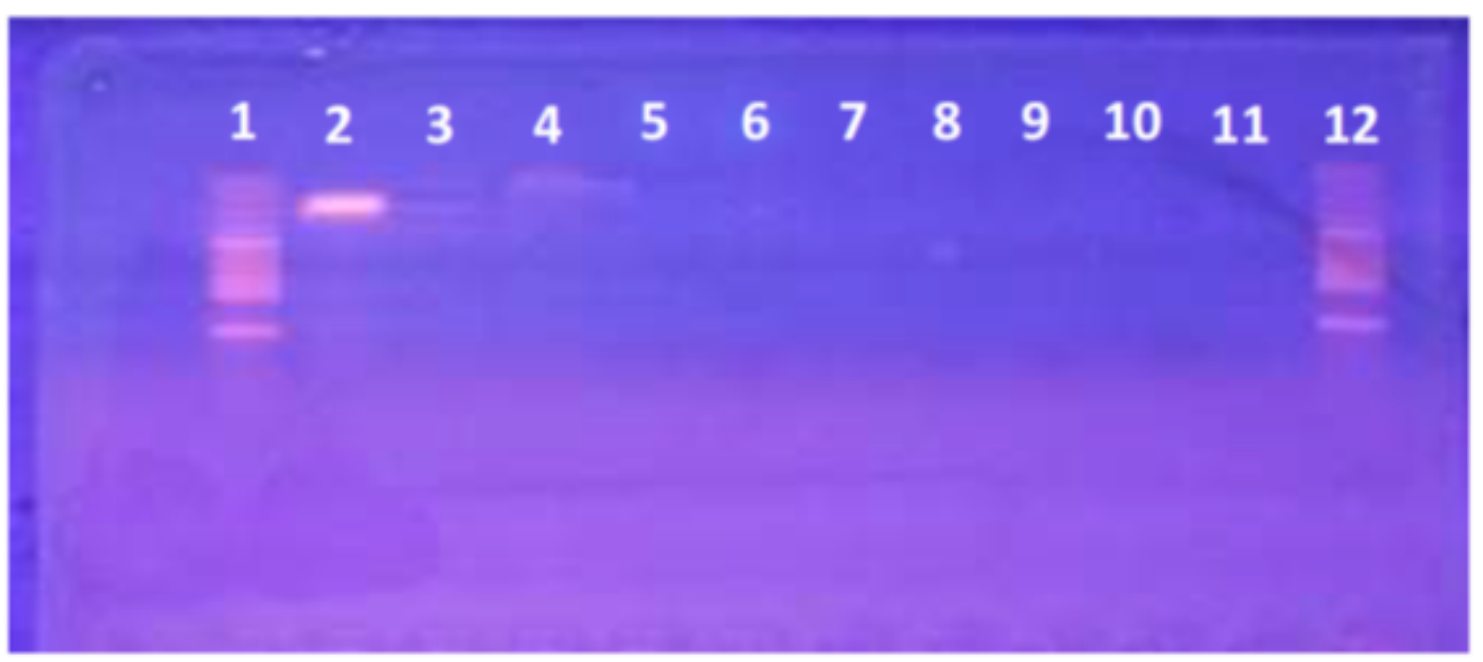

\section{Figure 2}

Agarose gel electrophoresis showing the characteristic band (251 bp) of $5^{\prime}$ untranslated region amplification in the positive control case (Lane 2), Lanes 1 and 12: Ladder, Lane 11: negative control, Lanes 3 to 10: study samples (with no amplified bands) 